\title{
Noninvasive ventilation as a weaning-facilitating strategy
}

\author{
P Guijo González", JM Estella, A Ramos Rodríguez, M Jaen Franco, M Recuerda, T Rico Armenteros, \\ L Fernández Ruiz, A Jareño Chaumel
}

From ESICM LIVES 2015

Berlin, Germany. 3-7 October 2015

\section{Introduction}

Extubation of critically ill patients with cardiac dysfunction and/or hypercapnic chronic obstructive pulmonary disease are probably one of the most common causes of weaning failure. Both extubation delay and especially the need for reintubation are associated with poor outcomes and an increase in morbidity.

\section{Objectives}

The aim of the present study was to evaluate the frequency of extubation failure in critically ill patients with chronic obstructive pulmonary disease (COPD) and/or cardiac failure and to analyze the efficacy of non invasive ventilation (NIV) applied inmediately after planned extubation.

\section{Methods}

Observational study performed in a 17 beds medicalsurgical ICU. Time of study was 14 months. Consecutive mechanically ventilated patients with COPD and/or cardiac failure were included. The variables analyzed were age, sex, ICU diagnosis, APACHE II at admission in ICU, fluid balance, ICU length of stay, tracheotomy, rate of reintubation. We distinguish two strategies of extubation based in physician's criteria according with or without the use of NIV after planned extubation.

\section{Results}

44 patients were finally included. 26 were treated with NIV immediately after planned extubation.

Shows clinical characteristics of patients analyzed. Reintubation rate was significantly lower in the NIV after extubation strategy subgroup of patients $(\mathrm{p}<0.05$, RR, 0.167; 95\% CI 0.029-0.953). In our series we observed a higher mortality in extubated patients without use of NIV.

\section{Conclusions}

A high rate of reintubation was observed in mechanically ill patients with COPD and/or cardiac failure.

Preventive use of NIV immediately after planned extubation was associated with a minor reintubation rate. NIV may be considered like an useful tool in patients with high risk of developing respiratory failure after extubation.

Table 1. Study characteristics

\begin{tabular}{lll}
\hline & $\begin{array}{l}\text { NIV after extubation } \\
\text { strategy (n: 26) }\end{array}$ & $\begin{array}{l}\text { Extubation without } \\
\text { NIV (n: 18) }\end{array}$ \\
\hline Age & 68 & 66 \\
\hline Apache II at admission & 22.3 & 21.1 \\
\hline 24 h fluid balance & -1126 & -1979 \\
\hline $\begin{array}{l}\text { Ventilator Associated } \\
\text { Pneumonia (\%) }\end{array}$ & $7.7 \%$ & $11.1 \%$ \\
\hline ARDS (\%) & $11.5 \%$ & $5.6 \%$ \\
\hline Tracheotomy (\%) & $0 \%$ & $11.1 \%$ \\
\hline ICU lenght of stay & 10.4 & 9.6 \\
\hline Reintubation rate (\%) & $7.7 \%$ & $33.3 \%$ \\
\hline Mortality (\%) & $3.8 \%$ & $11.1 \%$ \\
\hline
\end{tabular}

Published: 1 October 2015

doi:10.1186/2197-425X-3-S1-A171

Cite this article as: Guijo González et al:: Noninvasive ventilation as a weaning-facilitating strategy. Intensive Care Medicine Experimental 2015 3(Suppl 1):A171. 